\title{
Risk Profiles Associated with Endometriosis among Infertile Women
}

\author{
JAGLUL HAIDER KHAN', SAIFUR RAHMAN², CHOWDHURY TASLIMA NASREEN², \\ JAHANGIR ALAM ${ }^{4}$, PERVIN FATEMA ${ }^{5}$
}

\begin{abstract}
:
Background: Endometriosis is a common gynaecological disorder which is found in about $5 \%$ of women and in $30 \%$ of infertile women. Identification of risk factors and timely intervention is useful.
\end{abstract}

Methods: A case control study was conducted in the Dept. of obs \& gynae of Bangabandhu Sheikh Mujib Medical University, Shahbag, Dhaka, from October 2015 to March 2016 on 50 infertile patients attending the Infertility unit of the institute with the objective to determine the risk factors of endometriosis. Twenty five women with endometriosis was taken as cases (group-I) and twenty five women without endometriosis was taken as controls (group-II).

Result: The mean age was $32.8 \pm 5.4$ years in group I and $35.1 \pm 5.7$ years in group /I which is similar. Urban residents were 3.21 times (with 95\% Cl 0.87-12.71\%) more likely to develop endometriosis than rural resident which was statistically significant $(p<0.05)$.

Among the study population BMI of $72 \%$ patients in group I and $68 \%$ in group II were within $19-24 \mathrm{~kg} / \mathrm{m}^{2}$. The difference was not statistically significant $(p>0.05)$. There was not statistically significant difference ( $p>0.05$ ) between two groups in OCP use (84\%vs80\%).

Women with endometriosis had less physical activity than the women without endometriosis; the differences was statistically significant $(p<0.05)$. Consumption of caffeine, red meat, vegetables and fruits has no effect on endometriosis. Women with pain during menstruation were 29.33 times (with 95\% Cl 5.17-100\%) and women with heavy amount of blood flow were 5.09 times (with $95 \% \mathrm{Cl} 1.24-22.06 \%$ ) more likely to be endometriosis, which was statistically significant $(p<0.05)$. Other risk factors like- age, occupation, educational status, age at menarche and cycle length were not significantly $(p>0.05)$ associated with endometriosis.

Conclusion: Urban residence and all types of physical activities d"1 hour per day were significantly higher in infertile women with endometriosis.

Keyword: Risk factors of endometriosis, physical activity and endometriosis, urban residence and endometriosis.

\section{Introduction:}

Endometriosis is a common gynecological disorder in which endometrial tissue (glandular epithelium and stroma) is found outside the uterine cavity. ${ }^{1}$ It has been estimated to affect $2.5-3.3 \%$ of women of childbearing age. ${ }^{2}$ Clinical presentations of

1. Associate Professore,Gynae, Mugda Medical College, Dhaka

2. Consultant, Gynae, Sadar Hospital, Bhola.

3. Consultant, Gynae, DMCH.

4. Senior Consultant,Gynae, 250 Beded Hospital, Naryangong.

5. Chairman Dept.Of Obs \& Gynae, BSMMU.

Address of Correspondence: Dr. Jaglul Haider Khan, Associate Professore, Dept. of Gynae, Mugda Medical College, Dhaka. Email: jaglul_bd@yahoo.com, Mobile: 01711138525 
endometriosis varies from asymptomatic to symptoms including dysmenorrhea, dyspareunia, pelvic pain, abnormal menstrual bleeding (menorrhagia and/or metrorrhagia), subfertility and infertility. 3,4

Although the pathogenesis of endometriosis is still unknown, the most common etiology is believed to involve retrograde menstruation. Almost all women have some menstrual effluent that passes through the fallopian tubes during menstruation, but only a minority develops endometriosis due to the fact that those cells can be cleared by peritoneal macrophages. ${ }^{5}$

One of the most important complications of endometriosis is reduced fertility and infertility. Although endometriosis affects approximately $5 \%$ of the general population, its prevalence may be as high as $30 \%$ in infertile women. ${ }^{6}$

One of the challenging subjects in endometriosis is lack of non-invasive tests by which accurate diagnosis can be made. ${ }^{5}$ Endometriosis is always finally diagnosed by visualizing the lesions, cysts, implants, and nodules by laparoscopy. Nevertheless, there are accompanying symptoms that may be indicative such as pelvic pain, adnexal masses, and dyspareunia ${ }^{7}$ or some biochemical markers which are useful in detecting and monitoring endometriosis such as cancer antigen-125 (CA-125). ${ }^{8}$

In order to facilitate diagnosis of endometriosis by non-invasive methods, it is very important to know the risk factors which make women susceptible to endometriosis. By knowing the risk factors, women who may be at a high risk of developing endometriosis may be recognized earlier so that serious complications of endometriosis such as infertility can be prevented by diagnosis and treatment of women suffering from endometriosis in earlier stages (I and II).

Several studies have showed that age, race, body mass index (BMI), alcohol usage, and cigarette smoking were associated with the incidence of endometriosis in the USA ${ }^{9}$. They also stated that some of these associations may differ by infertility status at the time of laparoscopic diagnosis. ${ }^{9}$ CalhazJorge et al. ${ }^{10}$ found that prevalence of endometriosis in subfertile women was related to race, $\mathrm{BMI}$, irregular menstrual cycles, intensity of menstrual flow, dysmenorrhea, chronic pelvic pain, obstetrics history, oral contraceptive pills (OCPs) use, and smoking habits. ${ }^{10}$.

Endometriosis is a disease with pain and infertility. For endometriosis there is no obvious cause or cure. The symptoms of endometriosis, although characteristic, are extremely variable and not related to the stage of the disease. Furthermore, a variety of factors, including general health, depression, anxiety, and psychosocial attitudes, environmental factors, seem to affect the perception of symptoms and the need for medical attention. ${ }^{11-12}$ Treatment of infertile women with endometriosis is difficult and expensive. Identification of risk factors of this patients and treating them is an ideal approach to reduce disease progression. It will be significantly helpful for infertile women with endometriosis of our country with limited resource.

\section{Methods:}

A case control study was conducted at the Infertility unit of the Dept of Obstetrics and Gynecology, Bangabandhu Sheikh Mujib Medical University, Shahbag, Dhaka during the period October 2015 to march 2016 among the infertile patients attending the Infertility unit of the Department.

Fifty infertile women with or without endometriosis were selected by inclusion \& exclusion criteria by purposive sampling. Twenty five women with endometriosis was taken as cases (group-l) and twenty five women without endometriosis was taken as controls (group-II).

Inclusion criteria women of reproductive age group, women having history of infertility (primary or secondary), women either diagnosed as a case of endometriosis (by laparoscopy/ laparotomy/ sonographic evidence of having chocolate cyst) or not. Exclusion criteria was women beyond reproductive age group.

Data was collected in a structured data collection sheet after taking history from the patient requested physical examination and procedure performed and from hospital indoor documents i.e. patient chart and treatment record.

Statistical analysis was carried out by using the Statistical Package for Social Sciences version 16.0 for Windows. The mean values were calculated for continuous variables. The quantitative observations were indicated by frequencies and percentages. Chi- 
Square test was used to analyze the categorical variables, shown with cross tabulation. Student t-test was used for continuous variables. $P$ values $<0.05$ was considered as statistically significant. Ethical permission was taken from the Institute. All patients were explained about their conditions. The study did not interfere with the patient management nor deal with moral or social issues. Informed written consent was obtained.

\section{Results:}

The mean age was found $32.8 \pm 5.4$ years in group -I and 35.1 \pm 5.7 years in group- II. Which was similar (Table-I). So was the occupation and level of education of the women. Residents in urban area were $18(72 \%)$ in group I and $11(44 \%)$ in group II. This difference was statistically significant $(p<0.05)$ between the two groups. Considering the body mass index of the study population, $72.0 \%$ patients in group I and $68.0 \%$ in group II were within BMI 19.0-24.0 $\mathrm{kg} / \mathrm{m}^{2}$. The difference was not statistically significant $(p>0.05)$ between two groups. (Table-l)

In group I, 84\% women used OCP and 80\%in group II. The difference was not statistically significant $(p>0.05)$ between two groups.

Combining hours of physical activity (walking, house hold work, exercise/swimming and climbing stairs) women with endometriosis had less physical activity than the women without endometriosis. The differences were statistically significant $(p<0.05)$ between two groups (Table-III).

Women having total activity $<4$ hours per day were 4.75 times (with $95 \% \mathrm{Cl} 1.21-19.59 \%$ ) more likely to develop endometriosis. Women who walk d"1 hour per day are 8.50 times (with $95 \% \mathrm{Cl} 2.00-38.95 \%$ ) more likely to develop endometriosis. Those who do house hold work $\geq 1$ hour per day are 3.78 times (with $95 \% \mathrm{Cl} 1.01-14.63 \%$ ) more likely to develop endometriosis. Those who exercise/swimm d" 1 hour per day are 13.50 times (with $95 \% \mathrm{Cl} 2.88-70.41 \%$ )

Table-I

Distribution of the study population by particulars of the patients $(n=50)$

\begin{tabular}{|c|c|c|c|c|c|}
\hline \multirow[t]{2}{*}{ Particular of the patients } & \multicolumn{2}{|c|}{ Group-I (n=25) } & \multicolumn{2}{|c|}{ Group-II $(n=25)$} & \multirow[t]{2}{*}{ P value } \\
\hline & $\mathrm{n}$ & $\%$ & $\mathrm{n}$ & $\%$ & \\
\hline \multicolumn{6}{|l|}{ Age (in years) } \\
\hline$<30$ & 6 & 24.0 & 4 & 16.0 & \\
\hline $30-35$ & 10 & 40.0 & 7 & 28.0 & \\
\hline $36-40$ & 7 & 28.0 & 10 & 40.0 & \\
\hline$>40$ & 2 & 8.0 & 4 & 16.0 & \\
\hline Mean $\pm S D$ & 32.8 & \pm 5.4 & 35.1 & \pm 5.7 & ${ }^{\mathrm{a}} 0.150^{\mathrm{ns}}$ \\
\hline Range (min-max) & 21 & -42 & 20 & -44 & \\
\hline \multicolumn{6}{|l|}{ Occupational status } \\
\hline House wife & 18 & 72.0 & 17 & 68.0 & ${ }^{b} 0.758^{n s}$ \\
\hline Working lady & 7 & 28.0 & 8 & 32.0 & \\
\hline \multicolumn{6}{|l|}{ Residence } \\
\hline Urban & 18 & 72.0 & 11 & 44.0 & ${ }^{b} 0.045^{s}$ \\
\hline Rural & 7 & 28.0 & 14 & 56.0 & \\
\hline \multicolumn{6}{|l|}{ Educational status } \\
\hline SSC /O Level or below & 5 & 20.0 & 11 & 44.0 & \\
\hline HSC/A level & 11 & 44.0 & 10 & 40.0 & ${ }^{\mathrm{b}} 0.121^{\mathrm{ns}}$ \\
\hline Graduate\&above & 9 & 36.0 & 4 & 16.0 & \\
\hline \multicolumn{6}{|l|}{ BMI $\left(\mathrm{kg} / \mathrm{m}^{2}\right)$} \\
\hline$<19.0$ (underweight) & 2 & 8.0 & 3 & 12.0 & \\
\hline $19.0-24.0$ (normal) & 18 & 72.0 & 17 & 68.0 & ${ }^{\mathrm{b}} 0.892^{\mathrm{ns}}$ \\
\hline >24.0 (Overweight) & 5 & 20.0 & 5 & 20.0 & \\
\hline
\end{tabular}

$\mathrm{s}=$ significant, $\mathrm{ns}=$ not significant

ap value reached from unpaired t-test

${ }^{b} \mathrm{P}$ value reached from chi square test

Group I= Infertile women with endometriosis

Group II= Infertile women without endometriosis 
more likely to develop endometriosis. Women who climb upstairs d" 1 hour per day are 4.13 times (with $95 \% \mathrm{Cl} 0.82-23.19 \%)$ more likely to develop endometriosis (Table-III)

Regarding food habits of the study population, consumption of caffeine, red meat, vegetables and fruits, there were no significant $(p>0.05)$ difference between two groups (Table-IV).

Patients experiences pain during menstruation were 29.33 times (with 95\% Cl 5.17-100\%) more likely to diagnosed as endometriosis, which was statistically significant $(p<0.05)$ between two groups.
Patients with heavy amount of blood flow were 5.09 times (with $95 \% \mathrm{Cl} 1.24-22.06 \%$ ) more likely to be endometriotic, which was statistically significant $(p<0.05)$ between two groups(Table-II )

Urban residents were 3.21 times (with $95 \% \mathrm{Cl} 0.87$ $12.71 \%$ ) more likely to develop endometriosis, which was statistically significant $(p<0.05)$ between two groups.

Other risk factors like- age, educational status, age at menarche and menstrual cycle length were not significantly $(p>0.05)$ associated with endometriosis.

Table-II

Distribution of the study population by menstrual history $(n=50)$

\begin{tabular}{|c|c|c|c|c|c|}
\hline \multirow[t]{2}{*}{ Menstrual history } & \multicolumn{2}{|c|}{ Group-I $(n=25)$} & \multicolumn{2}{|c|}{ Group-II $(n=25)$} & \multirow[t]{2}{*}{$P$ value } \\
\hline & $\mathrm{n}$ & $\%$ & $\mathrm{n}$ & $\%$ & \\
\hline \multicolumn{6}{|c|}{ Age at menarche (years) } \\
\hline$\leq 11$ & 6 & 24.0 & 4 & 16.0 & \\
\hline 12 & 10 & 40.0 & 7 & 28.0 & $0.458^{\text {ns }}$ \\
\hline 13 & 5 & 20.0 & 10 & 40.0 & \\
\hline$\geq 14$ & 4 & 16.0 & 4 & 16.0 & \\
\hline \multicolumn{6}{|c|}{ Cycle length (in day) } \\
\hline$\leq 25$ & 18 & 72.0 & 16 & 64.0 & \\
\hline $26-31$ & 6 & 24.0 & 7 & 28.0 & $0.768^{\text {ns }}$ \\
\hline$>31$ & 1 & 4.0 & 2 & 8.0 & \\
\hline
\end{tabular}

Cycle pattern

$\begin{array}{lccccc}\text { Regular } & 20 & 80.0 & 23 & 92.0 & 0.209^{\text {ns }} \\ \text { Irregular } & 5 & 20.0 & 2 & 8.0 & \end{array}$

Amount of flow

$\begin{array}{lccccc}\text { Light } & 5 & 20.0 & 6 & 24.0 & \\ \text { Moderate } & 6 & 24.0 & 14 & 56.0 & 0.022^{\mathrm{s}} \\ \text { Heavy } & 14 & 56.0 & 5 & 20.0 & \end{array}$

Pain associated with menstruation

\begin{tabular}{cccccc} 
Yes & 22 & 88.0 & 5 & 20.0 & $0.001^{\text {s }}$ \\
No & 3 & 12.0 & 20 & 80.0 & \\
\hline
\end{tabular}

$\mathrm{s}=$ significant, $\mathrm{ns}=$ not significant

$P$ value reached from chi square test 
Table-III

Distribution of the study population by physical activity $(n=50)$

\begin{tabular}{|c|c|c|c|c|c|c|c|}
\hline & Gro & $=25)$ & Grol & $=25)$ & OR & $95 \% \mathrm{Cl}$ & $P$ value \\
\hline & $\mathrm{n}$ & $\%$ & $\mathrm{n}$ & $\%$ & & (Lower-upper) & \\
\hline Total activity & & & & & & & \\
\hline$<4$ hours per day & 19 & 76.0 & 10 & 40.0 & 4.75 & $1.21-19.59$ & $0.010^{\mathrm{s}}$ \\
\hline$\geq 4$ hours per day & 6 & 24.0 & 15 & 60.0 & & & \\
\hline Walking & & & & & & & \\
\hline$\leq 1$ hour per day & 20 & 80.0 & 8 & 32.0 & 8.50 & $2.00-38.95$ & $0.001^{\mathrm{s}}$ \\
\hline$>1$ hours per day & 5 & 20.0 & 17 & 68.0 & & & \\
\hline House hold work & & & & & & & \\
\hline$\leq 1$ hour per day & 17 & 68.0 & 9 & 36.0 & 3.78 & $1.01-14.63$ & $0.024^{\mathrm{s}}$ \\
\hline$>1$ hours per day & 8 & 32.0 & 16 & 64.0 & & & \\
\hline Exercise/swimming & & & & & & & \\
\hline$\leq 1$ hour per day & 21 & 84.0 & 7 & 28.0 & 13.50 & $2.88-70.41$ & $0.001^{\mathrm{s}}$ \\
\hline$>1$ hours per day & 4 & 16.0 & 18 & 72.0 & & & \\
\hline Climbing stairs & & & & & & & \\
\hline$\leq 1$ hour per day & 22 & 88.0 & 16 & 64.0 & 4.13 & $0.82-23.19$ & $0.047^{s}$ \\
\hline$>1$ hours per day & 3 & 12.0 & 9 & 36.0 & & & \\
\hline
\end{tabular}

OR=Odds ratio

Cl-Confidence interval

$\mathrm{s}=$ significant

$P$ value reached from chi square test

Table-IV

Distribution of the study population by food habits $(n=50)$

\begin{tabular}{|c|c|c|c|c|c|}
\hline \multirow[t]{2}{*}{ Food habits } & \multicolumn{2}{|c|}{ Group-I $(n=25)$} & \multicolumn{2}{|c|}{ Group-II $(n=25)$} & \multirow[t]{2}{*}{$P$ value } \\
\hline & $\mathrm{n}$ & $\%$ & $\mathrm{n}$ & $\%$ & \\
\hline \multicolumn{6}{|l|}{ Caffeine consumption } \\
\hline$\leq 1$ time per week & 10 & 40.0 & 9 & 36.0 & \multirow{3}{*}{$0.624^{\mathrm{ns}}$} \\
\hline$>1$ times per week & 5 & 20.0 & 3 & 12.0 & \\
\hline None & 10 & 40.0 & 13 & 52.0 & \\
\hline \multicolumn{6}{|l|}{ Red meat consumption } \\
\hline$\leq 1$ time per week & 2 & 8.0 & 5 & 20.0 & \multirow{3}{*}{$0.133^{\text {ns }}$} \\
\hline$>1$ times per week & 1 & 4.0 & 4 & 16.0 & \\
\hline None & 22 & 88.0 & 16 & 64.0 & \\
\hline \multicolumn{6}{|l|}{ Vegetables consumption } \\
\hline$\leq 1$ time per week & 8 & 32.0 & 9 & 36.0 & \multirow{3}{*}{$0.845^{\mathrm{ns}}$} \\
\hline$>1$ times per week & 4 & 16.0 & 5 & 20.0 & \\
\hline None & 13 & 52.0 & 11 & 44.0 & \\
\hline \multicolumn{6}{|l|}{ Fruits consumption } \\
\hline$\leq 1$ time per week & 4 & 16.0 & 8 & 32.0 & \multirow{3}{*}{$0.122^{\mathrm{ns}}$} \\
\hline$>1$ times per week & 2 & 8.0 & 5 & 20.0 & \\
\hline None & 19 & 76.0 & 12 & 48.0 & \\
\hline
\end{tabular}

ns $=$ not significant

$P$ value reached from chi square test 


\section{Discussion:}

Chaichian et al. ${ }^{13}$ evaluated some of the clinical predictive factors among Iranian infertile population. Clinical characteristics were compared with laparoscopic results. No statistically significant difference was identified in the participants' age, educational level, duration of breast-feeding, duration of infertility, and menstrual flow. On the contrary, women with endometriosis had longer duration of marriage $(O R=1.03, P<0.05)$, older age at first pregnancy $(\mathrm{OR}=1.21, \mathrm{P}<0.05)$, lower $\mathrm{BMI}(\mathrm{OR}=$ $0.9, P<0.05)$, shorter interval of menses $(O R=0.98$, $P<0.05$ ), and history of irregular menstrual cycles (OR $=0.54, \mathrm{P}<0.05)$, compared to those without endometriosis.

Yasui et al. ${ }^{14}$ examined risk profiles in imagingdiagnosed endometriosis with and without surgical confirmation in a large population of Japanese women. Two hundred and ten women had surgically confirmed endometriosis (Group A), 120 had imaging diagnosed endometriosis without a surgical procedure (Group B), and 264 had adenomyosis (Group C). A short menstrual cycle at 18-22 years of age and cigarette smoking at 30 years of age were associated with significantly increased risk of endometriosis (Group A plus Group B), while older age was associated with risk of adenomyosis (Group C).

Darwish et al. ${ }^{15}$ estimated the prevalence of typical and atypical (subtle) pelvic endometriosis as diagnosed by laparoscopy, and to define risk factors for this disease among Egyptian women. Laparoscopically, 469 patients $(18.8 \%)$ were diagnosed to be endometriosis. Of those, typical and atypical endometriosis were diagnosed in 220 patients $(8.8 \%)$ and 249 patients $(9.98 \%)$ respectively. Concerning risk factors, only decreased patient's age (less than 30 years), low parity, and urban residence were significantly correlated with endometriosis.

Calhaz-Jorge et al. ${ }^{10}$ evaluated the demographic and clinical characteristics in a cohort of Portuguese subfertile women in relation to the presence of endometriosis. Primary subfertility, regularity of menstrual cycles, dysmenorrhoea, chronic pelvic pain, obesity, ever use of oral contraceptives and smoking were the most important predictors of endometriosis.
Endometriosis is commonly found on the ovaries and is characterized by a range of symptoms and severity, including chronic pelvic pain and infertility. The role of modifiable exogenous factors such as exercise in the development of this disease is not well understood.

In this study mean age was $32.8 \pm 5.4$ years (range 21-42 yrs) in cases and 35.1 \pm 5.7 years (range 20 $44 \mathrm{yrs}$ ) in control. In the study of Chaichian et al. ${ }^{13}$ the mean age was $30.23 \pm 6.22$ years in endometriosis group and $29.02 \pm 5.96$ years in control group. Similar age range also observed by Moini et al. ${ }^{16}$; Dhillon and Holt. ${ }^{4}$ On the other hand in the study by Darwish et al. ${ }^{15}$ mean age was $26.8 \pm 5.3$ years and $29.0 \pm 5.3$ years in case and control respectively. Mean age of cases and controls are a little higher in our study than that of others.

Regarding occupational status, it was observed that, majority were housewives $(72.0 \%$ in cases and $68.0 \%$ controls). Moini et al. ${ }^{16}$ found that housewives was $40.7 \%$ and employee was $32.3 \%$ in their study patients, which is lower than our study.

In our study residents in urban area were $72.0 \%$ in cases and $44.0 \%$ in controls and In Darwish et al. ${ }^{15}$ study, urban residence was $71.1 \%$ in case and $45.3 \%$ in control. Which is comparable to the finding of current study. Increased prevalence of endometriosis in urban women may be explained by their medical awareness and educational level. Urban residence is associated with increasing problems of pollution. There is a possible link between endometriosis and one of the most harmful components of pollution, dioxin. ${ }^{17}$

It this study there was no significant difference in educational status of women with or without endometriosis which is consistent with the findings of study conducted by Darwish et al. ${ }^{15}$; An Italian group ${ }^{18}$; Berube et al. ${ }^{19}$ found no relation between education and presence of endometriosis. Chaichian et al. ${ }^{13}$ reported that there was no difference regarding educational level of two groups.

In this study $72.0 \%$ patients in group I and $68.0 \%$ in group II were within BMI $19.0-24.0 \mathrm{~kg} / \mathrm{m}^{2}$. The difference was not statistically significant $(p>0.05)$ between two groups, a findings similar with that of Darwish et al. ${ }^{16}$ study. Moini et al. ${ }^{15}$ obtained that $\mathrm{BMI}$ had an inverse correlation with endometriosis as infertile obese women were at lower risk for 
endometriosis $(p<0.05)$. Similar finding was also observed by Missmer et al. ${ }^{9}$; Calhaz-Jorge et al. ${ }^{10}$; Hediger et al. ${ }^{20}$. In contrast, Hemmings et al. ${ }^{21} \mathrm{did}$ not find any significant correlation between $\mathrm{BMI}$ and endometriosis similar to our study.

The exact relationship of oral contraceptive pills to the risk of endometriosis is controversial. ${ }^{21}$ In our study it was observed that more women (84.0\%) used OCP in group I than group II (80.0\%). The difference was not statistically significant $(p>0.05)$. Darwish et al. ${ }^{15}$ found oral contraceptive use of $5.9 \%$ in women with endometriosis and $7.9 \%$ in women without endometriosis. The difference was statistically significant $(p<0.05)$ between two groups. In another study Dhillon and Holt ${ }^{4}$ found current oral contraceptive use was $5.2 \%$ patients in case group and $23.2 \%$ in control group. Previously oral contraceptive users were $81.9 \%$ in case group and $64.3 \%$ in control group. Total absence of oral contraceptive use was $13.0 \%$ in case group and $12.6 \%$ in control group, which are comparable with the current study.

Regarding the menstrual history it was observed in this study that more women with endometriosis had short menstrual cycle than women without endometriosis. The difference was not statistically significant $(p>0.05)$ between two groups. Heavy amount of flow and pain associated with menstruation were significantly higher in women with endometriosis. Matalliotakis et al. ${ }^{5}$ showed that shorter cycle length and heavier menstrual cycles were associated with endometriosis. Also other groups of researchers such as Arumugam and $\mathrm{Lim}^{22}$. Cramer and Missmer ${ }^{23}$ revealed that women with a menstrual cycle shorter than 27-28 days had higher risk of developing endometriosis. On the other hand, Calhaz-Jorge et al. ${ }^{10}$; Hemmings et al. ${ }^{21}$ Parazzini et al. ${ }^{24}$ did not find any significant correlation between shorter menstrual cycle and endometriosis. In addition, Mamdouh et al. ${ }^{25}$ found that women with irregular cycles were three times more likely to develop endometriosis than women with regular cycles, which is inconsistent with our finding. In another study Chaichian et al. ${ }^{13}$ found that irregular menstruation was $18.3 \%$ in endometriosis group and $29.2 \% \%$ in non endometriosis group. The above findings closely differ from the findings of current study.
Dhillon and Holt ${ }^{4}$ found no association between "any physical activity" during the 2 years prior to the reference date and risk of endometrioma after controlling for age, number of live births, oral contraceptive use, and cigarette smoking. To evaluate the effects of physical activity in accordance with public health recommendations. ${ }^{26}$ the authors focused on women who participated in high-intensity activity for at least 30 minutes per episode, three or more times per week, and 10 or more months per year. The risk of endometrioma was significantly lowered by $70.0 \%$ for consistent, high intensity exercisers in comparison to women reporting no highintensity activity during the 2 years prior to the reference date $(\mathrm{OR}=0.30$ with $95 \% \mathrm{Cl}: 0.12-0.74)$. A similar analysis focusing on the period between 12 and 21 years of age yielded a $35.0 \%$ reduced risk, although the association was non significant. One advantage of Dhillon and Holt ${ }^{4}$ study is that the intensity level of physical activity was based on the determination of metabolic equivalents for specific activities by using the recently updated Compendium of Physical Activities ${ }^{27}$ and not on a study subject's interpretation of "vigorous" or "regular" exercise. The investigators were also able to evaluate the combined effects of duration, frequency, and intensity level of physical activity and consequently activity levels suggested in public health recommendations. ${ }^{26}$ The inverse associations between physical activity and endometriotic disease in the present study are similar to those found in the two previous studies ${ }^{28-29}$ even though cases in Dhillon and Holt ${ }^{4}$ study were women with more severe disease and cases in previous studies had infertility-associated endometriosis, often a mild or moderate form of disease. In a crosssectional study in Norway, ${ }^{30}$ investigators compared women with and without a self reported diagnosis of endometriosis and did not find a reduced risk associated with "regular" exercise (OR $=0.7$ with $95 \%$ Cl: $0.3-1.5)$. In none of the two studies ${ }^{29-30}$ did the authors address whether the presence of preexisting disease may have influenced the levels of recent physical activity reported by endometriosis cases. Dhillon and Holt ${ }^{4}$ study was able to address this issue by obtaining exercise patterns during adolescence, a time when activity would unlikely be affected by undiagnosed disease.

In a case control study conducted by Parazzini et al. ${ }^{24}$ in Northern Italy, there was significant reduction in risk emerged for higher in take of green vegetables 
$(\mathrm{OR}=0.3$ for the highest tertile of intake) and fresh fruit $(O R=0.6)$, whereas an increased in risk was associated with high intake of beef and other red meet $(O R=2.0)$ and ham $(O R=1.8)$ Consumption of milk, liver, carrot, cheese, fish and whole grain foods as well as coffee and alcohol consumption were not significantly related with endometriosis. However, in our study it was observed that with regard to consumption of caffeine, red meat, vegetables and fruits there were no significant $(p>0.5)$ difference between two groups.

The study population was selected from one hospital of Dhaka city, so that the results of the study may not reflect the exact picture of the country. Small sample size was also a limitation of this study. Therefore, in future further study may be under taken with large sample size.

\section{Conclusion:}

This study was undertaken to determine the risk factors of endometriosis in infertile women. Most of the infertile women were in $3^{\text {rd }}$ decade and housewives. Use of oral contraceptive use have no relation with endometriosis. Urban residence, heavy amount of flow, pain associated with menstruation and all types of physical activities d" 1 hour per day were significantly higher in infertile women with endometriosis. Regarding food habits like consumption of caffeine, red meat, vegetables and fruits, there were no significant ( $p>0.05)$ association with endometriosis.

Age, educational status, age at menarche and menstrual cycle length were not significantly $(p>0.05)$ associated with endometriosis.

\section{References:}

1. Hart R. Unexplained infertility, endometriosis and fibroids. BMJ. 2003; 327: 721-4.

2. Houston DE, Noller KL, Melton LJ, Selwyn BJ, Hardy RJ. Incidence of pelvic endometriosis in Rochester, Minnesota, 1970-1979. Am J Epidemiol. 1987; 125: 959-69.

3. Marino JL, Holt VL, Chen C, Davis S. Life time occupational history and risk of endometriosis. Scand J Work Environ Health. 2009; 35: 23340.

4. Dhillon PK, Holt VL. Recreational physical activity and endometrioma risk. Am J Epidemiol. 2003; 158: 156-64.
5. Matalliotakis IM, Cakmak H, Fragouli YG, Goumenou AG, Mahutte NG, Arici A. Epidemiological characteristics in women with and without endometriosis in the Yale series. Arch Gynecol Obstet. 2008; 277: 389-93.

6. Witz CA, Burns WN. Endometriosis and infertility: is there a cause and effect relationshps? Gynecol Obstet Invest. 2002; 53: 2-11.

7. Melis GB, Ajossa S, Guerriero S. Epidemiology and diagnosis of endometriosis. Ann N Y Acad Sci. 1994; 734: 352-7.

8. Szubert M, Suzin J, Wierzbowski T, KowalczykAmico K. CA-125 concentration in serum and peritoneal fluid in patients with endometriosis preliminary results. Arch Med Sci. 2012; 8: 504-8.

9. Missmer SA, Hankinson SE, Spiegelman D, Barbieri RL, Marshall LM, Hunter DJ. Incidence of laparoscopically confirmed endometriosis by demographic, anthropometric, and lifestyle factors. Am J Epidemiol. 2004; 160: 784-96.

10. Calhaz-Jorge C, Mol BW, Nunes J, Costa AP. Clinical predictive factors for endometriosis in a Portuguese infertile population. Hum Reprod. 2004; 19: 2126-31.

11. Parazzini F, Ferraroni M. Epidemiology of endometriosis. BMJ 1993; 306: 930-1.

12. Vessey MP, Villard-Mackintosh L, Painter R. Epidemiology of endometriosis in women attending family planning clinics. BMJ 1993; 306: 182-4.

13. Chaichian S, Mehdizadehkashi A, Najmi Z, Mobasseri A, Jahanloo A, Mohabbatian B et al. Clinical Predictive Factors for Diagnosis of Endometriosis in Iranian Infertile Population. J Minim Invasive Surg Sci. 2015; 4(3): 1-4.

14. Yasui T, Hayashi K, Nagai K, Mizunuma H, Kubota T, Lee JS et al. Risk Profiles for Endometriosis in Japanese Women: Results From a Repeated Survey of Self-Reports. J Epidemiol 2015; 25(3): 194-203.

15. Darwish AM, Hassanin MS, Abou Sekkin IA. Epidemiology and risk factors associated with laparoscopically diagnosed typical and atypical endometriosis among Egyptian women. Middle 
East Fertility Society Journal 2006; 11(3): 196-201.

16. Moini A, Malekzadeh F, Amirchaghmaghi E, Kashfi F, Akhoond MR, Saei M et al. Risk factors associated with endometriosis among infertile Iranian women, Arch Med Sci. 2013; 9(3): 50614.

17. Koninckx PR. The physiopathology of endometriosis: pollution and dioxin. Gynecol Obstet Invest 1999; 47(1): 47-9.

18. Gruppo Italiano per lo Studio dell' endometriosi. Risk factors for pelvic endometriosis in women with pelvic pain or infertility. Eur $\mathrm{J}$ Obstet Gynecol Reprod Biol 1999; 83: 195-9.

19. Berube $S$, Marcoux $S$, Maheux R. Characteristics related to the prevalence of minimal or mild endometriosis in infertile women. Canadian Collaborative Group on Endometriosis. Epidemiology 1998; 9(5): 50410.

20. Hediger ML, Hartnett HJ, Louis GM. Association of endometriosis with body size and figure. Fertil Steril 2005; 84: 1366-74.

21. Hemmings R, Rivard M, Olive DL, Poliquin-Fleury J, Gagne D, Hugo P, Gosselin D. Evaluation of risk factors associated with endometriosis. Fertil Steril 2004; 81(6): 1513-21.

22. Arumugam K, Lim JM. Menstrual characteristics associated with endometriosis. $\mathrm{Br} \mathrm{J}$ Obstet Gynaecol 1997; 104: 948-50.
23. Cramer DW, Missmer SA. The epidemiology of endometriosis. Ann N Y Acad Sci 2002; 955: 11-22.

24. Parazzini F, Di Cintio E, Chatenoud L, Moroni $S$, Mezzanotte C, Crosignani PG. Oral contraceptive use and risk of endometriosis. Italian Endometriosis Study Group. Br J Obstet Gynaecol 1999; 106: 695-9.

25. Mamdouh HM, Mortada MM, Kharboush IF, Abd-Ela-teef HA. Epidemiologic determinants of endometriosis among Egyptian women: a hospital-based case-control study. J Egypt Public Health Assoc 2011; 86: 21-6.

26. Pate RR, Pratt M, Blair SN. Physical activity and public health. JAMA 1995; 273: 402-7.

27. Ainsworth BE, Haskell WL, Whitt MC. Compendium of physical activities: an update of activity codes and MET intensities. Med Sci Sports Exerc 2000; 32: S498-516.

28. Cramer DW, Wilson E, Stillman RJ. The relation of endometriosis to menstrual characteristics, smoking, and exercise. JAMA 1986; 255: 1904-8.

29. Signorello LB, Harlow BL, Cramer DW. Epidemiologic determinants of endometriosis: a hospital-based case-control study. Ann Epidemiol 1997; 7: 267-74.

30. Moen $\mathrm{MH}$, Schei B. Epidemiology of endometriosis in a Norwegian county. Acta Obstet Gynecol Scand 1997; 76: 559-62. 